\title{
Controversies in the Treatment of Abdominal Aortic Aneurysm (1): Is the NICE Guideline Nice to Patients?
}

\author{
Seung-Kee Min \\ Division of Vascular Surgery, Department of Surgery, Seoul National University College of Medicine, Seoul, Korea
}

"Everything you see is real.

Things are never ideal. There is nothing in between."

- Aristotle -

1 recently had an interesting experience choosing treatment for abdominal aortic aneurysm (AAA) (Fig. 1). A 60-year-old man visited our vascular clinic with an incidental AAA. He had already visited two other famous tertiary referral centers in Seoul, Korea, where he was given different recommendations of open aneurysm repair (OAR) and endovascular aneurysm repair (EVAR), and wanted a second opinion. 1 carefully reviewed his medical history and computed tomography (CT) angiogram and found that the aneurysm was only $4.7 \mathrm{~cm}$ measured outer-to-outer in perpendicular plane to the aneurysm axis. The diameters in the axial view were $4.5 \mathrm{~cm} \times 5.6 \mathrm{~cm}$. Therefore, 1 explained that the treatment threshold was $5.5 \mathrm{~cm}$, and any kind of operation, such as OAR or EVAR (Fig. 2), was not necessary. In addition, only routine surveillance of the AAA was required. Despite fully understanding the situation, he was not happy with my opinion. As expected, he was lost to follow-up, probably because the already-heard threat of rupture and sudden death overwhelmed his thoughts. 1 asked my colleagues serious questions: "What lies between the ideal situation and reality?", "How closely are we following current guidelines?", and "What are the guidelines for?"

This reminds me of the recent debates of the UK National Institute for Health and Care Excellence (NICE) guideline draft, which recommends against the use of EVAR for unruptured AAA in most circumstances [1]. It concluded that EVAR is not cost-effective and suggested that patients with a large intact AAA should not be offered EVAR if they are fit enough for OAR. This draft was released in May 2018, feedback was solicited from all stakeholders involved in AAA treatment, and it evoked great turmoil among vascular specialists worldwide who have espoused endovascular therapy for aortic diseases. In every international meeting for vascular specialists, debate and criticism of the NICE draft were widespread. The main criticisms, listed by liapis et al. [2] and elsewhere, are criticized or accepted by many surgeons:

(1) NICE recommendations are based on outdated data ( September 2016). This criticism is not acceptable because a guideline cannot be created in a year; in fact, it was the product of four years' work by NICE and the AAA guideline development committee;

(2) NICE does not comply with European Society for Vascular Surgery (ESVS) or Society for Vascular Surgery (SVS) guidelines. This is true because the NICE had somewhat different views and focused on the formal clinical and costeffective analysis of randomized controlled trials (RCTs). In a country with limited health resources, cost-effectiveness is an important factor in deciding the treatment modality for the greatest happiness of the greatest number;

(3) The NICE used only RCTs and dismissed large nonrandomized cohorts and registries. This criticism is also faulty. In every guideline, the level of evidence is an important factor in persuading readers to follow it. In the tree of evidence, meta-analyses and RCTs provide higher levels of evidence than large non-randomized cohorts and registry cohorts, which usually have more bias. Guideline committees usually include RCTs only but sometimes includes nonrandomized studies if insufficient RCTs are available;

(4) The loss of elective EVAR skills affects the EVAR competency in cases of ruptured AAA. This complaint seems reasonable. In ruptured AAA cases, the EVAR pro-

Corresponding author: Seung-Kee Min, Division of Vascular Surgery, Seoul National University Hospital, 101 Daehak-ro, Jongno-gu, Seoul 03080, Korea

Tel: 82-2-2072-0297, Fax: 82-2-766-3975, E-mail: skminmd@snuh.org, https://orcid.org/0000-0002-1433-2562

Copyright (c) 2021 The Korean Society for Vascular Surgery

This is an Open Access article distributed under the terms of the Creative Commons Attribution Non-Commercial License (http://creativecommons.org/licenses/by-nc/4.0) which permits unrestricted non-commercial use, distribution, and reproduction in any medium, provided the original work is properly cited.

Cite this article; Vasc Specialist Int 2021. https://doi.org/10.5758/vsi.213741 


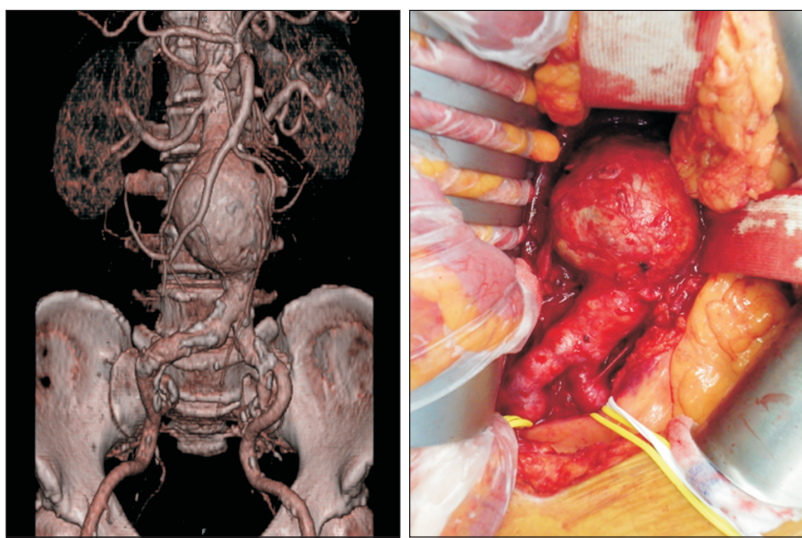

Fig. 1. Abdominal aortic aneurysm.

cedure is usually performed quickly under stressful conditions, which requires experienced teamwork. If elective EVAR experience is lacking, more difficult ruptured EVAR cannot be performed successfully;

(5) NICE contains the impact of unsolved political issues between vascular surgery and interventional radiology in the UK. This issue points out that most EVAR procedures in the UK are performed by interventional radiologists, not vascular surgeons. However, this criticism is not scientific and insults vascular surgeons who are not performing EVAR by themselves;

(6) NICE diminishes the expertise of vascular surgeons. This seems to be the main reason why many vascular specialists objected to the NICE draft. However, this is neither scientific nor ethical. The first modern Hippocratic oath is "Do no harm," which means "Do what's best for the patient, not what's best for you";

(7) The NICE dismissed patient preference for the clinical decision-making process. This criticism is important and reasonable. Because of the minimally invasive nature of EVAR and lack of a long abdominal scar and pain, reducing the hospital stay duration and 30-day mortality rate, many patients choose EVAR. Vascular specialists should offer objective data on EVAR, discuss the advantages and risks of each treatment modality, and help patients choose the optimal treatment for them. If patients are concerned about early mortality, scarring, or postoperative pain, EVAR may be a better option. If patients are concerned about longterm reintervention and surveillance, OAR may be the best option. However, consideration of the cost burden on the national health resources is necessary for optimizing limited healthcare resources.

Finally, in March 2020, NICE published its final version of the AAA guidelines that included significant changes according to the stakeholders' feedback [3]. The major changes include EVAR as a reasonable option for AAA
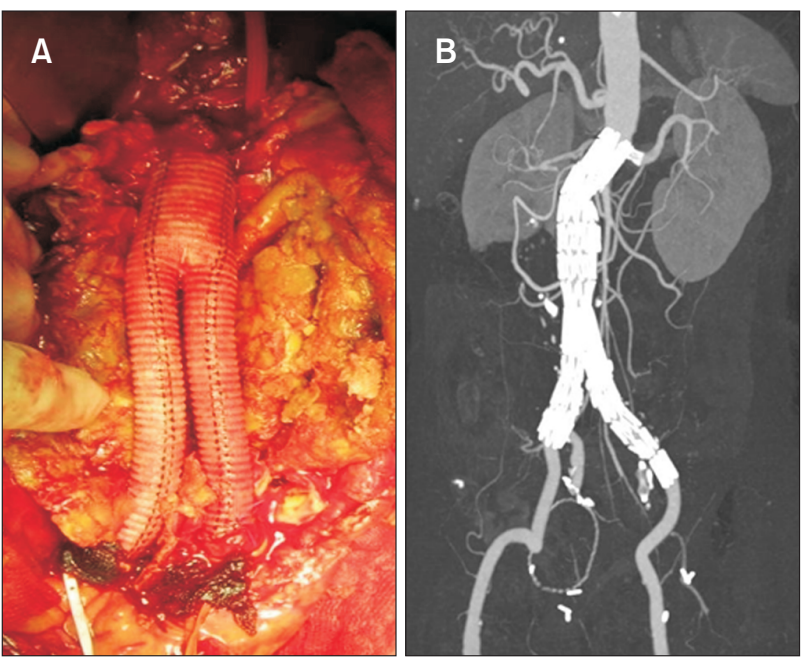

Fig. 2. Open surgical repair (A) and endovascular repair (B) of abdominal aortic aneurysm.

management under certain conditions with abdominal co-pathology. NICE introduced patient preference in the decision-making process. In brief, it states: "For people with unruptured AAAs, offer OAR unless it is contraindicated because of abdominal co-pathology (hostile abdomen, horseshoe kidney, or stoma), anesthetic risks, and/or medical comorbidity. Consider EVAR in patients who have abdominal co-pathology or other considerations specific to and discussed with the patient. Consider EVAR or conservative management in patients who have anesthetic risks and/ or medical comorbidities."

Some interpreted this as "a nice U-turn" [4], while others termed it "an unexplained U-turn" [5,6]. Chrisp [6] insisted that it was not a U-turn because the revision reflects evidence and stakeholder feedback; in particular, the need to steer the system to shift practice toward open surgery over time as well as acknowledging the importance of patient preferences and informed choice. 1 think the final version of the NICE guideline is indeed nice to patients because it introduces patient choice and recommends cost-effective treatment based on high-quality evidence. 1 agree and hope that the NICE guidelines will be well received by most vascular specialists worldwide and ultimately benefit AAA patients.

Moreover, the NICE guideline provides an important description of AAA size measurements that is not included in the ESVS or SVS guidelines. The inner-to-inner maximum anteroposterior aortic diameter on ultrasound should be measured (NICE guideline 1.5.1). This endorses the method used in the UK screening program. The inner-to-inner ultrasound measurement records an aortic diameter that is approximately $0.5 \mathrm{~cm}$ smaller than that on CT [4]. However, 
many surgeons use the longest aortic diameter on the CT axial plane to obtain a reimbursement threshold of $5.5 \mathrm{~cm}$. This reflects another cause of the overtreatment of small AAAs that lacks evidence. Although the patient was lost to follow-up and was probably treated at another hospital, 1 and my colleagues strictly adhered to the guidelines with a treatment threshold of $5.5 \mathrm{~cm}$ by correct measurement. Additionally, Hinchliffe and Earnshaw [4] mentioned that "If the guidelines simply make vascular surgeons think more carefully before using an EVAR device off instruction for use, they will have been worthwhile." That is what the guidelines for and different guidelines have their own mes- sages.

\section{CONFLICTS OF INTEREST}

Seung-Kee Min has been the editor-in-chief of Vasc Specialist Int since 2019.

\section{ORCID}

\author{
Seung-Kee Min \\ https://orcid.org/0000-0002-1433-2562
}

\section{REFERENCES}

1) National Institute for Health and Care Excellence (NICE). Abdominal aortic aneurysm: diagnosis and management. NICE guideline - draft for consultation [Internet]. London: National Institute for Health and Care Excellence; C 2018 [cited 2021 Dec 10]. Available from: https://www.nice.org. uk/guidance/ng156/documents/shortversion-of-draft-guideline.

2) Liapis CD, Avgerinos ED, Eckstein $\mathrm{HH}$. Proposed NICE abdominal aortic aneurysm repair guidelines: swinging the pendulum too far? Eur J Vasc En- dovasc Surg 2019;58:637-638.

3) National Institute for Health and Care Excellence (NICE). Abdominal aortic aneurysm: diagnosis and management, NICE guideline NG156 [internet]. London: National Institute for Health and Care Excellence; C 2020 [cited 2021 Dec 10]. Available from: https:// www.nice.org.uk/guidance/ng156.

4) Hinchliffe RJ, Earnshaw JJ. Endovascular treatment of abdominal aortic aneurysm: a NICE U-turn. Br J Surg 2020;107:940-942.

5) Hammond C, Bradbury A. NICE's guideline on the management of people with an Abdominal Aortic Aneurysm: an unexplained U turn [Internet]. London: the BMJ opinion; C 2020 [cited 2021 Dec 10]. Available from: https://blogs.bmj.com/ bmj/2020/11/27/nices-guideline-onthe-management-of-people-withan-abdominal-aortic-aneurysm-anunexplained-u-turn/.

6) Chrisp P. Comment on: endovascular treatment of abdominal aortic aneurysm: a NICE U-turn. Br J Surg 2020;107:e281. 